\title{
The possibility of applying acoustic emission method to optimize determination of milling parameters
}

\author{
KRZYSZTOF DUDZIK \\ Marine Maintenance Department \\ Gdynia Maritime University \\ 81-225 Gdynia, Morska 81-87 \\ POLAND
}

\begin{abstract}
Nowadays acoustic emission (AE) method is used in many fields of science, including in the diagnosis and monitoring of machining processes such as turning, grinding, milling, etc. Monitoring of milling process allows to ensure stable conditions of treatment. Stable conditions of milling process have a great impact on the quality of the surface. There are different methods used for monitoring machining processes, i.e. dynamometer methods, thermography, vibrations measurement, acoustic emission, etc. The research was carried out on a universal FUW3157 III milling machine using end mills made of HSS. Tools were in different stages of wear. The research was carried out at constant rotational speed and variable other cutting parameters, i.e. feed, depth of cut. Milling process was performed on a sheet made of EN AW-7020 aluminium alloy. The milling process was monitored by an acoustic emission set made by Physical Acoustics Corporation (PAC). The PAC system consists of: preamplifier USB AE Node, type 1283 with bandpass $20 \mathrm{kHz}-1 \mathrm{MHz}, \mathrm{AE}$ signal measurement sensor type VS $150 \mathrm{M}$, with a frequency range $100-450 \mathrm{kHz}$, computer with AE Win for USB Version E5.30 software for recording and analysing AE data. During the study, the acoustic emission signals generated during milling process were recorded and then chosen parameters were analyzed e. g.: amplitude, number of events - hits, the effective value of the signal (RMS). The study can be the basis for the use of acoustic emission method for monitoring milling process and determining the parameters to ensure stable conditions of that process and the same to obtain a high quality surface.
\end{abstract}

Key-Words: - acoustic emission (AE), diagnostic, monitoring, milling, cutting parameters, optimization Received: February 6, 2020, Revised: July 1, 2020. Accepted: July 12, 2020. Published: August 6, 2020.

\section{Introduction}

Machining is still the most common method ensuring shape and dimensional requirements for forming of different materials, usually metals. Milling is one of them. Conventional machining accuracy is usually considered as a function of the characteristics of all the components of object, tool, fixture and machine. There are: accuracy performance, the accuracy of static and dynamic determining and cutting parameters, which are associated with strength, temperature and wear of the cutting edge $[1,2]$.

To obtain a high surface quality should be optimized determination of cutting parameters. Manufacturers of tools give ranges of recommended parameters, but in order to achieve the best possible surface area is necessary to define the exact parameters [3]. One of the criteria for ensuring high surface quality is reducing the tool vibration [4]. This is particularly important for finishing treatment. Additional advantage is longer tool operational time. Monitoring the tool wear allows obtaining high quality of machined surface and avoiding unplanned breaks in production caused by its catastrophic failure [5, 6, 7, 8]. On the other hand, there is requirement of possible the best machining efficiency which results in reducing production costs $[9,10]$.

There are many methods for monitoring and optimization of the machining process for selection of cutting parameters. One of them is the acoustic emission (AE) method [11]. According to the definition acoustic emission is an evanescent elastic wave, which is the result of rapid release of the energy accumulated in the material by propagating a micro-damage (increase in micro-cracks, the movement of groups of dislocations) in the material or by a process (friction, leakage, etc.) [12, 13, 14]. The frequency range of typical acoustic emission signal is usually determined in $20 \mathrm{kHz}-2 \mathrm{MHz}$ [15].

Acoustic Emission is considered as a passive non-destructive method. One of the advantages of using this method is the possibility of conducting continuous research without having to shut down equipment out of service. The sensitivity of $\mathrm{AE}$ is 
one of the highest of all methods. Lee et al. [16] reported that the $\mathrm{AE}$ technique has a higher sensitivity compared to other sensing systems due to its wide detection range. And last but not least is the possibility of locating the source of the AE signals generated by internal and external factors e.g.: cracks, leaks, etc.

The stimulus causing the release of energy and the formation of elastic waves can be: temperature change, environment, load operation, and the processes which are accompanied by acoustic emission changes both at the micro and the macro scale, such as: friction, cracks, plastic deformation, leaks, corrosion, chemical reactions, structural and phase changes, delamination, cracking of the fibers and matrix in composites, etc. [12,17].

The acoustic waves propagate in all directions from the source, can thus be detected by one or more sensors mounted on an object or component. Due to the phenomenon of wave attenuation during their propagation, the distance from which they are detectable is limited. This distance depends on many factors, including mainly material properties, object geometry and the level of interference from background noise [13, 17]. Examples of AE signals are shown in Fig. 1 and Fig. 2.

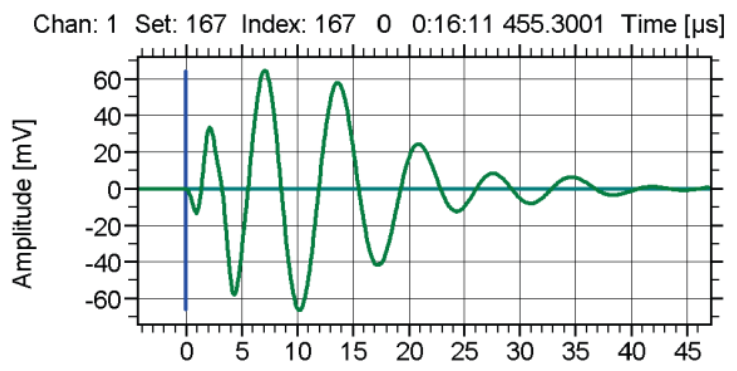

Fig. 1. Example of typical acoustic emission burst signal [15].

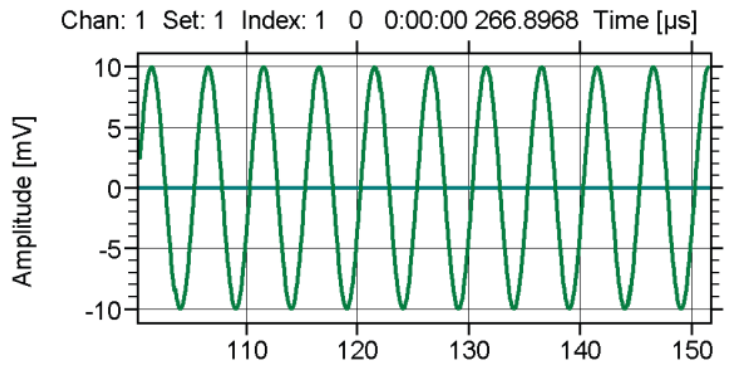

Fig. 2. Example of typical acoustic emission continuous signal [15].

AE signal can be characterized by parameters such as: number of exceedances of the threshold of discrimination - counts, hits, amplitude, duration, rise time, RMS and energy of the signal, etc. Schematic definition of the features of an AE signal are presented in Fig. 3.

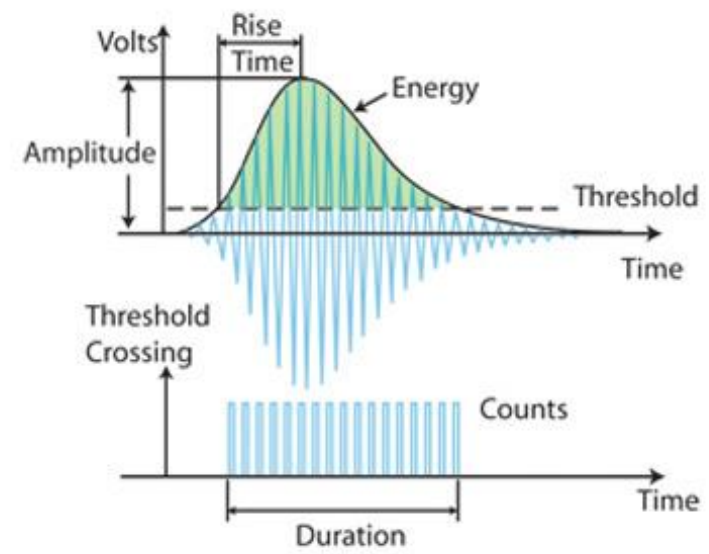

Fig. 3. The definitions for AE parameters [18].

This article presents the possibility of using acoustic emission method for optimizing the selection of cutting parameters during milling.

\section{Research methodology}

The research was carried out on a universal FUW3157 III milling machine using end mills made of HSS. Milling process was conducted without any cooling.

As a workpiece was used sheet made of AW7020 aluminium alloy. Sheet thickness was $20 \mathrm{~mm}$. The chemical composition of chosen alloy is presented in table 1 .

Table 1. Chemical composition of AW-7020 alloy

\begin{tabular}{|c|c|c|c|c|c|c|c|c|c|}
\hline \multicolumn{10}{|c|}{ Chemical composition (\%) } \\
\hline $\mathrm{Zn}$ & $\mathrm{Mg}$ & $\mathrm{Fe}$ & $\mathrm{Si}$ & $\mathrm{Mn}$ & $\mathrm{Cr}$ & $\mathrm{Cu}$ & $\mathrm{Zr}$ & $\mathrm{Ti}$ & $\mathrm{Al}$ \\
\hline 4.70 & 1.30 & 0.35 & 0.30 & 0.24 & 0.14 & 0.10 & 0.07 & 0.08 & bal. \\
\hline
\end{tabular}

The basis of cutting parameters selection was the recommendations of the tool manufacturer. The research was carried out at constant rotational speed $\mathrm{n}$ and changing feed and depth of cut. The cutting parameters are presented in table 2 .

Table 2. The cutting parameters of milling process

\begin{tabular}{|c|c|c|}
\hline & \multicolumn{2}{|c|}{ Cutting parameters } \\
\hline $\begin{array}{c}\mathbf{n} \\
{[\mathbf{r p m}]}\end{array}$ & \multicolumn{2}{|c|}{400} \\
\hline $\begin{array}{c}\mathbf{a p} \\
{[\mathbf{m m}]}\end{array}$ & 3.0 & 5.0 \\
\hline $\begin{array}{c}\mathbf{f} \\
{[\mathbf{m m} / \mathbf{m i n}]}\end{array}$ & $25 ; 30 ; 35$ & $25 ; 30 ; 35$ \\
\hline
\end{tabular}


Used four fleets end mills (3428 type) with a diameter of $20 \mathrm{~mm}$ in various degrees of wear: new, blunt, slightly blunt with broken one of blades. Selected tools are shown in Fig. 4 and the view of cutting edges in Fig. 5.

For monitoring the milling process acoustic emission method was used. Research of acoustic emission (AE) accompanying the milling process was performed using a kit from Physical Acoustics Corporation. The kit includes: AE-Sensor VS 150M (with a frequency range of $100-450 \mathrm{kHz}$ ), preamplifier with bandpass $75 \mathrm{kHz}-1.1 \mathrm{MHz}$, USB AE Node recorder, type 1283 with bandpass $20 \mathrm{kHz}-1 \mathrm{MHz}$ and computer. For recording and analysing $\mathrm{AE}$ data was used software $\mathrm{AE}$ Win for USB Version E5.30 designed for mentioned PAC system. The software enables recording of a raw signal and performing analyzes. Information is available on changes in individual parameters: amplitude, RMS, energy, hits and counts over time. It is possible to perform FFT (Fast Fourier Transform) analysis to find characteristic signal frequencies for individual phenomena. Analysis of rise time and signals duration allows to determine their character, e.g. whether it is a continuous or burst signal. Selecting available filters and changing the threshold settings makes it easier to separate the signal from the background noise.

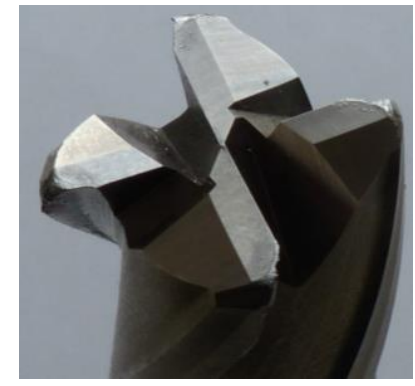

a)

Fig. 4. The view of the tools: a) blunt, b) with broken one of blades.

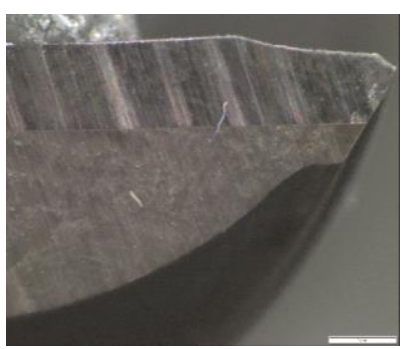

a)

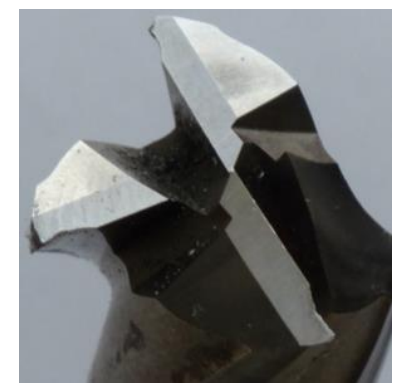

b)

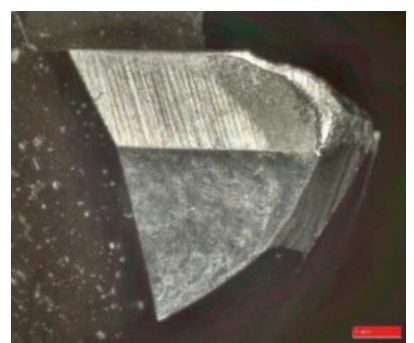

b)
Fig. 5. The view of cutting edges:

a) new tool, b) blunt tool.
The sensor was fixed to the surface of the vice, used as a workpiece holder, by dedicated magnetic holder. Between the sensor and the surface, the silicone grease was used as a coupling fluid.

A view of the laboratory stand is shown in Fig. 6.

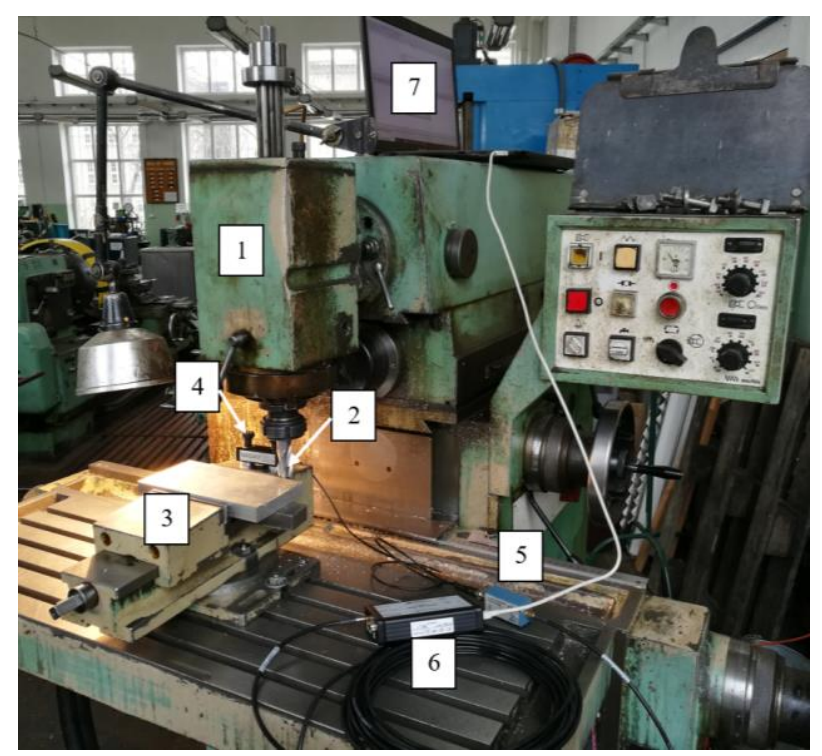

Fig. 6. The view of laboratory stand: $1-$ milling machine, 2 - tool, 3 - vice with workpiece, 4 - AE sensor with magnetic holder, 5 - preamplifier, 6 - AE recorder,

$$
7 \text { - computer. }
$$

\section{Research results}

During the study, the acoustic emission (AE) generated in the milling process carried out on a test, recorded a number of parameters which were analyzed. These parameters were e.g.: number of hits, amplitude, RMS, energy, etc. The analysis of that parameters was performed using $\mathrm{AE}$ Win for USB Version E5.30 software. The tests were repeated three times for all chosen parameters.

An example of graph presenting raw $\mathrm{AE}$ signal recorded in the tests - changing voltage as a function of time, is shown in Fig. 7.

The recorded signals were analyzed. Fig. 8 and Fig. 9 present selected charts: amplitude and RMS changes over time for the new tool. There is a significant decrease in RMS value after the initial running-in process of cutting edges in the tool. Signal was recorded during milling by new tool with parameters: $\mathrm{ap}=3 \mathrm{~mm}, \mathrm{f}=25 \mathrm{~mm} / \mathrm{min}$. 


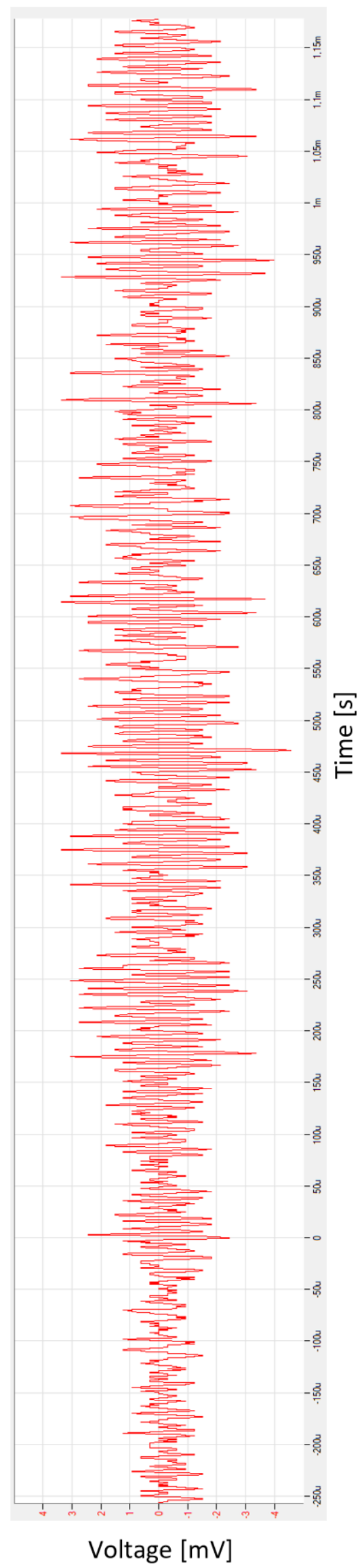

Fig. 7. An example of raw AE signal.

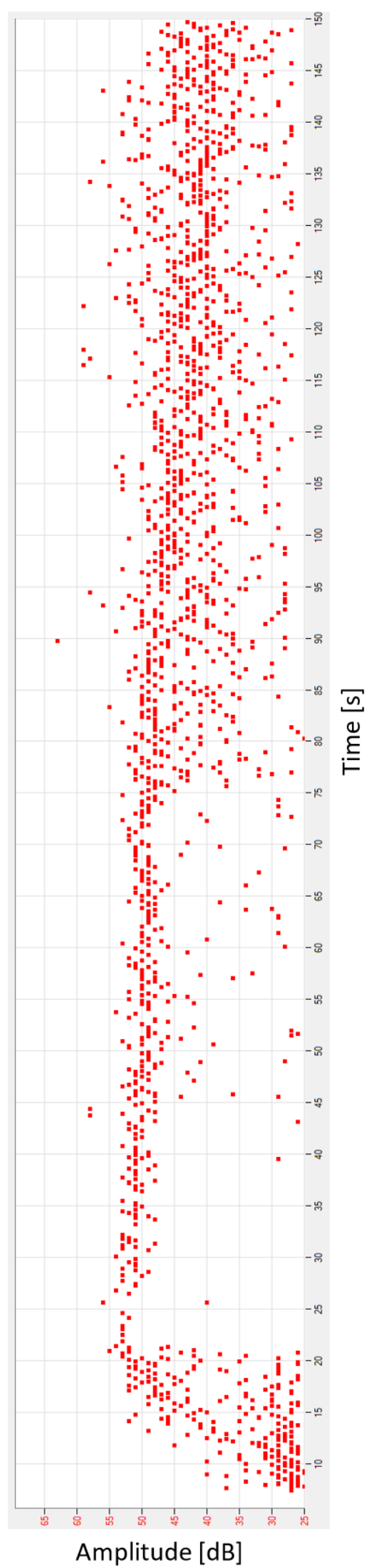

Fig. 8. Amplitude over time of AE signal for the new tool and parameters, $a p=3 \mathrm{~mm}, \mathrm{f}=25 \mathrm{~mm} / \mathrm{min}$. 


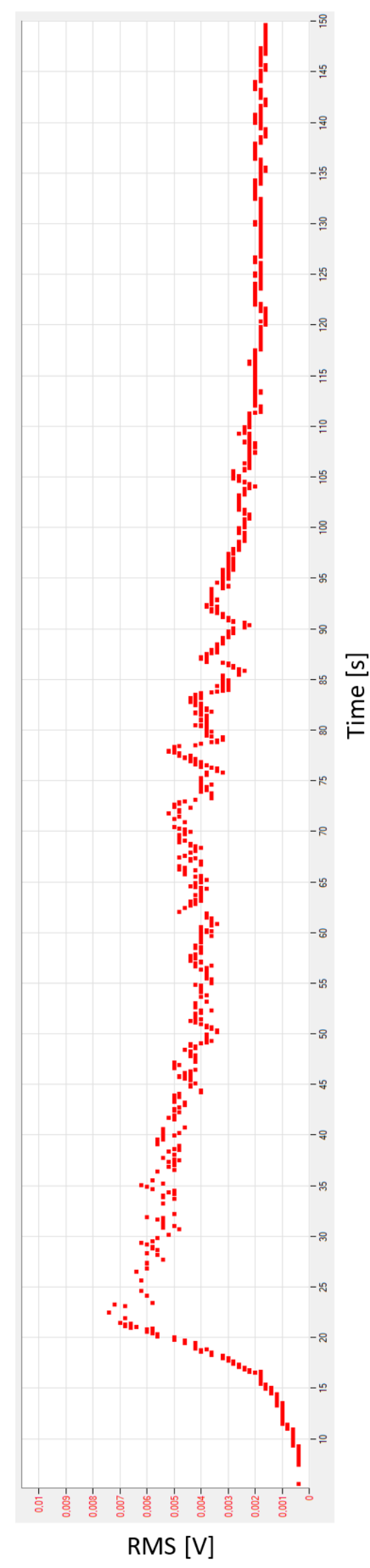

Fig. 9. RMS over time of AE signal for the new tool and parameters, $a p=3 \mathrm{~mm}, \mathrm{f}=25 \mathrm{~mm} / \mathrm{min}$.
Fig. 10 shows the change in signal amplitude as a function of time and their frequency.

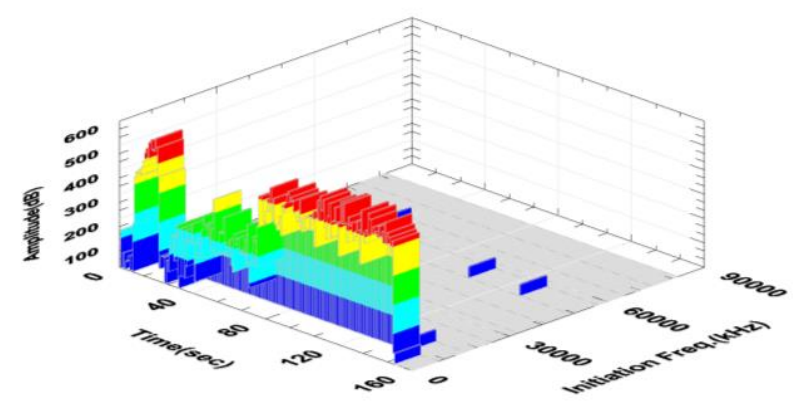

Fig. 10. AE signal for the new tool and parameters, $\mathrm{ap}=3 \mathrm{~mm}, \mathrm{f}=25 \mathrm{~mm} / \mathrm{min}-$ amplitude over time and frequency.

The low frequency character of recorded signal is characteristic for continuous signals, e.g. friction [2]. An increase of signal amplitude is visible along tool break-in time. High values of signal amplitude with simultaneous decrease in RMS indicate of low energy of events generating acoustic emission. It allows to conclude that the machining conditions have stabilized after the initial tool break-in process. Fig. 11 presents a chart of the number of AE hits over time. Here too, the break-in period is visible, followed by a stable milling process. The steady increase in the number of hits during milling, after about $75 \mathrm{~s}$, indicates machining stability.

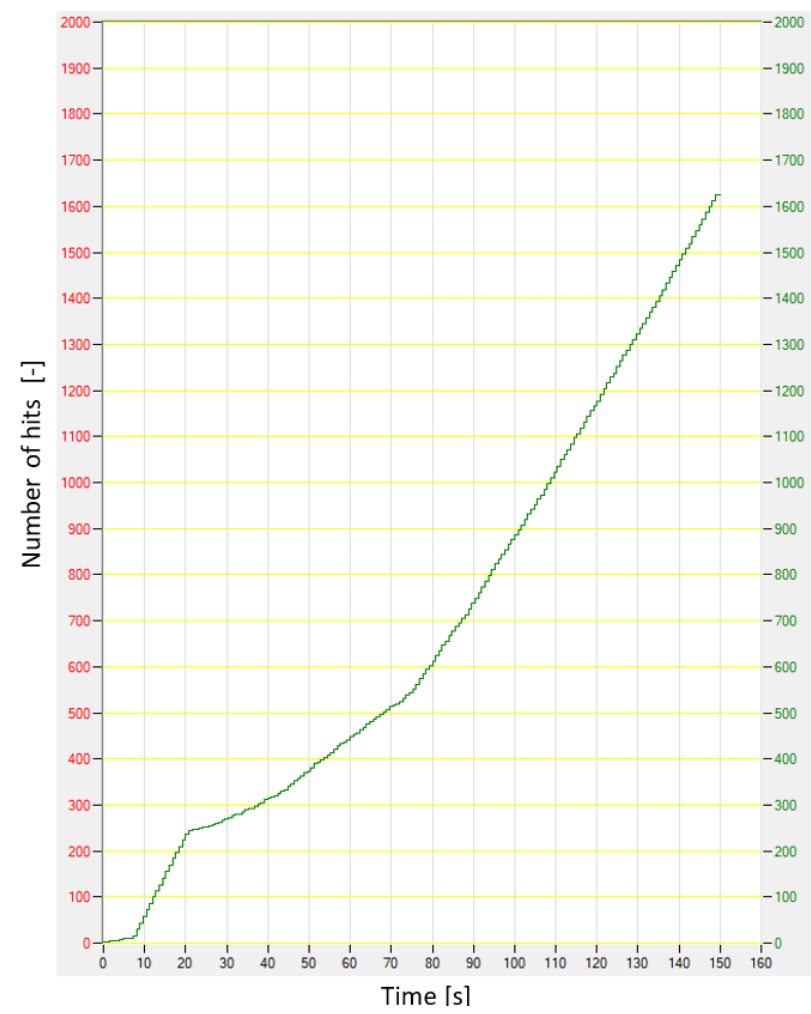

Fig. 11. AE signal for the new tool and parameters, $\mathrm{ap}=3 \mathrm{~mm}, \mathrm{f}=25 \mathrm{~mm} / \mathrm{min}-$ number of hits over time. 
The research results were shown in tables 3, 4 and 5 . Those are average values of chosen parameters: amplitude, RMS and AE hits of the signals and their standard deviation, for various wear stages of the tool.

Table 3. Research results for new tool

\begin{tabular}{|c|c|c|c|c|c|c|c|}
\hline \multicolumn{2}{|c|}{$\begin{array}{c}\text { Cutting } \\
\text { parameters }\end{array}$} & \multicolumn{6}{|c|}{ AE parameters } \\
\hline \multirow{2}{*}{$\begin{array}{c}\mathrm{f} \\
{[\mathrm{mm} /} \\
\mathrm{min}]\end{array}$} & \multirow[t]{2}{*}{$\begin{array}{c}\mathrm{ap} \\
{[\mathrm{mm}]}\end{array}$} & \multicolumn{2}{|c|}{$\begin{array}{c}\mathrm{A} \\
{[\mathrm{dB}]}\end{array}$} & \multicolumn{2}{|c|}{$\begin{array}{l}\text { RMS } \\
{[\mathrm{mV}]}\end{array}$} & \multicolumn{2}{|c|}{$\begin{array}{l}\text { hits } \\
{[-]}\end{array}$} \\
\hline & & mean & $\begin{array}{r}\text { std } \\
\text { dev. }\end{array}$ & mean & $\begin{array}{l}\text { std } \\
\text { dev. }\end{array}$ & mean & $\begin{array}{r}\text { std } \\
\text { dev. }\end{array}$ \\
\hline 25 & \multirow{3}{*}{3} & 41.84 & 6.41 & 2.20 & 0.56 & 531 & 751 \\
\hline 30 & & 31.32 & 4.86 & 1.04 & 0.14 & 52 & 112 \\
\hline 35 & & 38.55 & 7.01 & 1.72 & 0.25 & 446 & 656 \\
\hline 25 & \multirow{3}{*}{5} & 38.85 & 6.89 & 3.49 & 0.72 & 197 & 309 \\
\hline 30 & & 38.31 & 5.45 & 1.62 & 0.22 & 487 & 736 \\
\hline 35 & & 41.85 & 9.21 & 2.91 & 0.37 & 624 & 819 \\
\hline
\end{tabular}

Table 4. Research results for blunt tool

\begin{tabular}{|c|c|c|c|c|c|c|c|}
\hline \multicolumn{2}{|c|}{$\begin{array}{c}\text { Cutting } \\
\text { parameters }\end{array}$} & \multicolumn{6}{|c|}{ AE parameters } \\
\hline \multirow{2}{*}{$\begin{array}{c}\mathrm{f} \\
{[\mathrm{mm} /} \\
\mathrm{min}]\end{array}$} & \multirow[t]{2}{*}{$\begin{array}{c}\mathrm{ap} \\
{[\mathrm{mm}]}\end{array}$} & \multicolumn{2}{|c|}{$\begin{array}{c}\mathrm{A} \\
{[\mathrm{dB}]}\end{array}$} & \multicolumn{2}{|c|}{$\begin{array}{l}\mathrm{RMS} \\
{[\mathrm{mV}]}\end{array}$} & \multicolumn{2}{|c|}{$\begin{array}{l}\text { hits } \\
{[-]}\end{array}$} \\
\hline & & mean & $\begin{array}{l}\text { std } \\
\text { dev. }\end{array}$ & mean & $\begin{array}{l}\text { std } \\
\text { dev. }\end{array}$ & mean & $\begin{array}{r}\text { std } \\
\text { dev }\end{array}$ \\
\hline 25 & \multirow{3}{*}{3} & 30.55 & 5.03 & 1.03 & 0.12 & 41 & 103 \\
\hline 30 & & 29.64 & 4.44 & 0.92 & 0.11 & 32 & 140 \\
\hline 35 & & 30.54 & 4.82 & 0.98 & 0.14 & 40 & 98 \\
\hline 25 & \multirow{3}{*}{5} & 29.91 & 4.08 & 0.86 & 0.11 & 30 & 86 \\
\hline 30 & & 30.23 & 4.61 & 0.87 & 0.11 & 29 & 87 \\
\hline 35 & & 32.85 & 6.08 & 1.16 & 0.25 & 94 & 229 \\
\hline
\end{tabular}

Table 5. Research results for the tool with broken one of blades

\begin{tabular}{|c|c|c|c|c|c|c|c|}
\hline \multicolumn{2}{|c|}{$\begin{array}{c}\text { Cutting } \\
\text { parameters }\end{array}$} & \multicolumn{6}{|c|}{ AE parameters } \\
\hline \multirow{2}{*}{$\begin{array}{c}\mathrm{f} \\
{[\mathrm{mm} /} \\
\mathrm{min}]\end{array}$} & \multirow[t]{2}{*}{$\underset{[\mathrm{mm}]}{\mathrm{ap}}$} & \multicolumn{2}{|c|}{$\begin{array}{c}\mathrm{A} \\
{[\mathrm{dB}]} \\
\end{array}$} & \multicolumn{2}{|c|}{$\begin{array}{l}\text { RMS } \\
{[\mathrm{mV}]}\end{array}$} & \multicolumn{2}{|c|}{$\begin{array}{l}\text { hits } \\
{[-]}\end{array}$} \\
\hline & & mean & $\begin{array}{r}\text { std } \\
\text { dev. }\end{array}$ & mean & $\begin{array}{l}\text { std } \\
\text { dev. }\end{array}$ & mean & $\begin{array}{r}\text { std } \\
\text { dev }\end{array}$ \\
\hline 25 & \multirow{3}{*}{3} & 31.63 & 5.92 & 1.51 & 0.64 & 45 & 116 \\
\hline 30 & & 28.83 & 4.11 & 0.84 & 0.11 & 13 & 34 \\
\hline 35 & & 29.90 & 4.11 & 0.88 & 0.14 & 33 & 41 \\
\hline 25 & \multirow{3}{*}{5} & 32.05 & 5.54 & 1.02 & 0.12 & 86 & 171 \\
\hline 30 & & 29.61 & 4.71 & 0.83 & 0.11 & 18 & 53 \\
\hline 35 & & 29.95 & 4.53 & 0.94 & 0.27 & 22 & 68 \\
\hline
\end{tabular}

Analysis of test results showed, that the lowest values of amplitude, RMS and number of hits were obtained during milling with the parameters: ap $=3$ $\mathrm{mm}$ and $\mathrm{f}=30 \mathrm{~mm} / \mathrm{min}$. The application of these cutting parameters resulted in the generating of a signal with the lowest values of analyzed parameters, in all considered states of tool wear.

Examples of charts recorded during milling with selected optimal cutting parameters are shown in Fig. $12-14$.

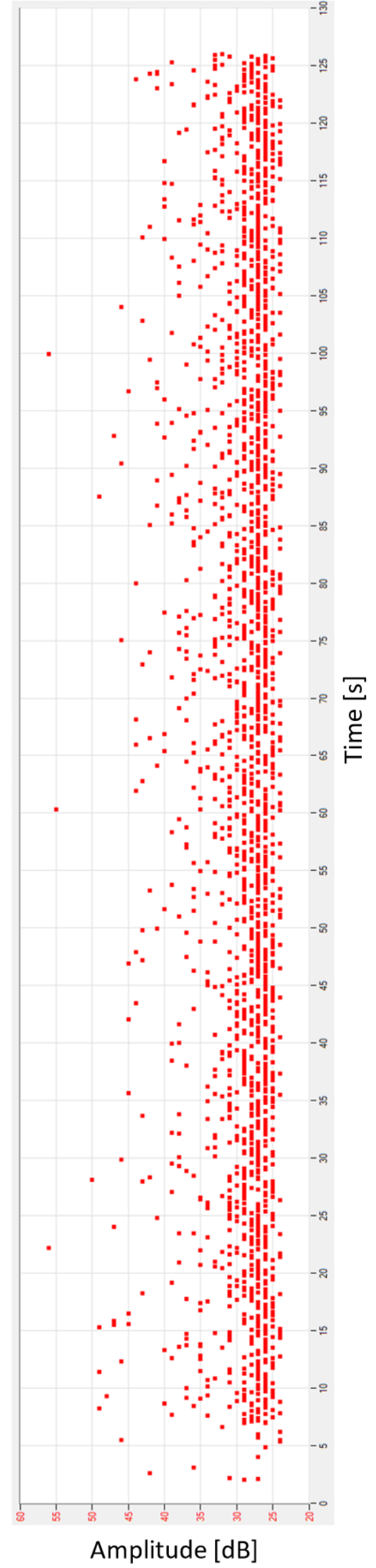

Fig. 12. Amplitude over time of AE signal for the broken tool and optimized parameters, $a p=3 \mathrm{~mm}, \mathrm{f}=30 \mathrm{~mm} / \mathrm{min}$. 


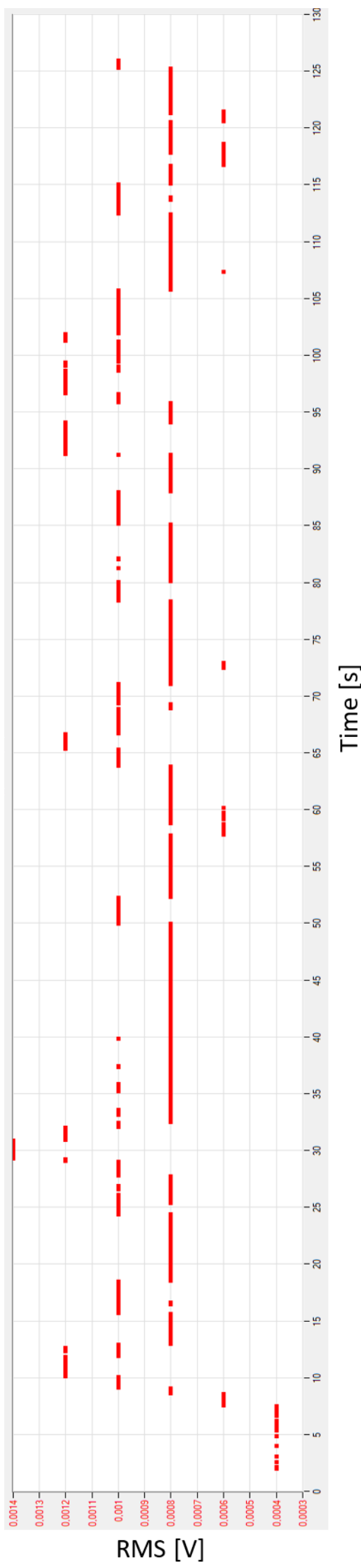

Fig. 13. RMS over time of AE signal for the broken tool and optimized parameters, $a p=3 \mathrm{~mm}, \mathrm{f}=30 \mathrm{~mm} / \mathrm{min}$.

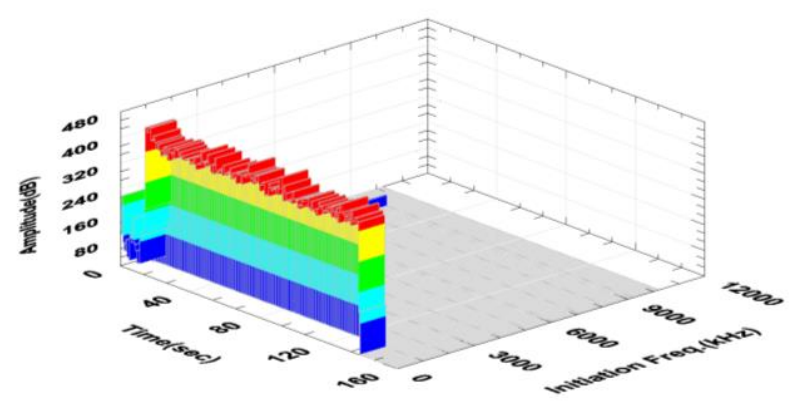

Fig. 12. AE signal for the broken tool and optimized parameters, $a p=3 \mathrm{~mm}, \mathrm{f}=30 \mathrm{~mm} / \mathrm{min}$ - amplitude over time and frequency.

Constant, relatively low values of the analyzed $\mathrm{AE}$ parameters, especially low frequency of the signal, indicate stable machining conditions throughout the entire milling process.

The low RMS value and the number of hits of the $\mathrm{AE}$ signals generated during machining processes may indicate stable machining conditions. The rule here is: the less, the better. Deterioration of machining conditions results in increased levels of vibration in the system, which ultimately affects the quality of the treated surface. Increasing the level of these phenomena is accompanied by the generation of $\mathrm{AE}$ signal with higher energy. Test results showed that blunting of cutting edges of tools was more important for machining conditions than breaking one of the blades while maintaining the remaining edges in good condition.

\section{Conclusion}

Correct machining parameters have a significant impact on machining stability and thus on the quality of the processed surface [3]. In addition, tool life is extended, which directly reduces machining costs [19].

The research was carried out at a constant rotational speed $n=400 \mathrm{rpm}$. End mills with a diameter of $20 \mathrm{~mm}$ were used in three levels of wear: new, blunt and slightly blunt with broken one of four blades. During the study, it was observed that in the first phase of milling with the new tool, the generated acoustic emission signal was clearly higher compared to the later phase of normal work. In that time the signal RMS has been reduced by more than $50 \%$. This was probably due to the breakin process of the tool [19]. It was observed that blunt tools worked more stable than the new one. The parameters of the signal recorded during milling both, with a blunt tool and without one of the blades were at a lower level compared to the new one. The analysis of the obtained test results 
showed that missing one cutting edge in the tool has no effect on the machining stability. The remaining 3 cutting edges were sufficient, with selected machining parameters, to ensure the correctness of the milling process.

Changes of selected cutting parameters caused changes in the acoustic emission signal generated during machining. The lowest values of amplitude, RMS and number of AE hits were recorded with the parameters: depth of cut ap $=3 \mathrm{~mm}$ and feed $\mathrm{f}=30$ $\mathrm{mm} / \mathrm{min}$. In the case of a blunt tool, changing the cutting parameters did not matter so much. In all considered tool states, the use of these parameters generated lower energy signals. In the case of a new tool and with one blade broken off, the appropriate selection of parameters resulted in a reduction of the signal RMS by about two times. A $25 \%$ decrease in RMS was observed for the blunt tool.

The specific values of the selected parameters describing the $\mathrm{AE}$ signal generated during milling are new in this article. The parameter with the highest diagnostic capabilities is the RMS. Based on this, operators can monitor the state of tool wear, but above all choose the machining parameters under conditions similar to those described in the test methodology. Selection of machining parameters on the basis of $\mathrm{AE}$ tests allows to ensure better machining conditions than just their selection according to the recommendations of the tool manufacturer.

The tests showed that the acoustic emission method can be used to optimize the selection of cutting parameters during milling. In further work it is planned to compare the results obtained with the $\mathrm{AE}$ method with other methods, e.g. measurement of forces during machining and temperature measurement.

\section{Acknowledgment}

This research was supported by National Science Center of Poland under the grant DEC2019/03/X/ST8/00372.

\section{References:}

[1] W. Labuda, The Influence of Treatments Conditions on Cutting Forces and Temperature during Finish Turning of Stainless Steel by CCET09T302R-MF. In Proceedings of 27th Anniversary International Conference on Metallurgy and Materials. Ostrava, Czech Republic, 2018, pp. 1163 - 1168.

[2] W. Labuda, The Influence of Cutting Parameters on Cutting Forces and Surface
Roughness, Journal of KONES Powertrain and Transport; Vol. 21, No. 3, 2014, pp. 199-204.

[3] A. Matras, W. Zębala, Optimization of Cutting Data and Tool Inclination Angles During Hard Milling with CBN Tools, Based on Force Predictions and Surface Roughness Measurements, Materials, Vol. 13, 1109, 2020.

[4] A.V. Filippov, A. Y. Nikonov, V. E. Rubtsov, A. I. Dmitriev, S. Tarasov, Vibration and Acoustic Emission Monitoring the Stability of Peakless Tool Turning: Experiment and Modelling, Journal of Materials Processing Technology, Vol. 246, 2017, pp. 224-234.

[5] V. Balsamo, A. Caggiano, K. Jemielniak, J. Kossakowska, M. Nejman, R. Teti, Multi Sensor Signal Processing for Catastrophic Tool Failure Detection in Turning, In Research and Innovation in Manufacturing: Key enabling technologies for the factories of the future Proceedings of the 48th CIRP Conference On Manufacturing Systems, Vol. 41, Ischia, Italy, 2016, pp. 939-944.

[6] D. K. Rao, K. Srinivas, An Analysis of Feature Identification for Tool Wear Monitoring by using Acoustic Emission, Traitement du Signal, Vol. 34, No. 3-4, 2017, pp. 117-135.

[7] A. Albers, T. Sturmlinger, K. Wantzen, G. Bartosz, F. Munke, Prediction of the Product Quality of Turned Parts by Real-Time Acoustic Emission Indicators. Manufacturing systems 4.0, In The 50th CIRP Conference on Manufacturing Systems, Procedia CIRP, Vol. 63, 2017, pp. 348-353.

[8] M. K. Babouri, N. Ouelaa, A. Djebala, Experimental Study of Tool Life Transition and Wear Monitoring in Turning Operation Using a Hybrid Method Based on Wavelet MultiResolution Analysis and Empirical Mode Decomposition, International Journal of Advanced Manufacturing Technology, Vol. 82, No. 9-12, 2016, pp. 2017-2028.

[9] R. Teti, K. Jemielniak, G. O'Donnell, D. Dornfeld, Advanced Monitoring of Machining Operations, CIRP AnnalsManufacturing Technology, Vol. 59, No. 2, 2010, pp. 717-739.

[10] F. Wu, X. Wang, W.W. Zhong, H. Yu, L. B. Liu, D. T. Liao, Based on Multi-sensor Tool Steel Hard Turning Process Monitoring and Controlling, Advanced Materials Research, Vol. 108-111, 2010, pp. 549-555.

[11] A. Hase, M. Wada, T. Koga, H. Mishina, The Relationship Between Acoustic Emission Signals and Cutting Phenomena in Turning Process, International Journal of Advanced 
Manufacturing Technology, Vol. 70, No. 5-8, 2014, pp. 947-955.

[12] I. Baran, M. Nowak, J. Schmidt, K. Ono, Potentials of AE Application in Testing Industrial Pipelines, Advances in Acoustic Emission, USA, 2007.

[13] B. Ziegler, A. Miszczak, Acoustic Emission as a Friction Force Indicator after Test Stands Experiments, Journal of KONES Powertrain and Transport, Vol. 14, No. 4, 2007, pp. 579586.

[14] K. Panasiuk, L. Kyziol, K. Dudzik, G. Hajdukiewicz, Application of the Acoustic Emission Method and Kolmogorov-Sinai Metric Entropy in Determining the Yield Point in Aluminium Alloy, Materials, Vol. 13, 2020, pp. 1378-1386.

[15] Vallen Systeme, AMSY-6 Handbook, Germany 2010.

[16] D. E. Lee, I. Hwang, C. M. O. Valente, J. F. G. Oliveira, D. A. Dornfeld, Precision Manufacturing Process Monitoring with Acoustic Emission, In: Wang L, Gao R. X. (eds) Cond. Monit. Control Intell. Manuf. Springer London, 2006, pp. 33-54.

[17] K. Dudzik, The Possibility of Application Acoustic Emission Method for Controlling Friction Stir Welding of AW-5083 Aluminium Alloy Sheets, In The 26th International Conference on Metallurgy and Materials, Tanger, Proceedings Paper, 2017, pp. 16951700.

[18] M. Huang, L. Jiang, P. K. Liaw, Ch. R. Brooks, R. Seeley, D. L. Klarstrom, Using Acoustic Emission in Fatigue and Fracture Materials Research, Nondestructive Evaluation: Overview, Vol. 50, No. 11, 1998.

[19] Y. S. Ahmed, A. F. M. Arif, S. C. Veldhuis, Application of the Wavelet Transform to Acoustic Emission Signals For Built-Up Edge Monitoring in Stainless Steel Machining, Measurement, Vol. 86, 2020, pp. 1-18.

\section{Creative Commons Attribution License 4.0 (Attribution 4.0 International, CC BY 4.0)}

This article is published under the terms of the Creative Commons Attribution License 4.0

https://creativecommons.org/licenses/by/4.0/deed.en US 